\title{
Interleukin-8 is not a predictive biomarker for the development of the acute promyelocytic leukemia differentiation syndrome
}

Luciana Yamamoto de Almeida 1,2, Diego Antonio Pereira-Martins ${ }^{1,2}$, Ana Sílvia Gouvêa Lima , Márcia Sueli Baggio³, Luisa Corrêa de Araujo Koury ${ }^{1}$, Ana Paula Lange ${ }^{1,2}$, Sarah Cristina Bassi ${ }^{2}$, Priscila Santos Scheucher ${ }^{1}$ and Eduardo Magalhães Rego ${ }^{1,2,4^{*}}$ (D)

\begin{abstract}
Background: Differentiation syndrome (DS) is the main life-threatening adverse event that occurs in acute promyelocytic leukemia (APL) patients treated with all-trans retinoic acid (ATRA). Cytokine imbalances have been reported to play role during the developing of acute promyelocytic leukemia differentiation syndrome (APL-DS). However, the relationship between the plasma cytokine levels and their prognostic value for the prediction of DS developing in patients with APL during the treatment with ATRA and anthracyclines has not been previously reported.

Methods: In this study, we followed an APL cohort $(n=17)$ over 7 days of ATRA therapy in DS $(n=6)$ and non-DS groups $(n=11)$. Interleukin (IL)-1 $\beta, \mathrm{LL}-6, \mathrm{IL}-8, \mathrm{LL}-10, \mathrm{LL}-12 \mathrm{p} 70$ and TNF-a were measured in the peripheral blood plasma from 17 patients with APL and 11 healthy adult controls by using the cytometric bead array method.

Results: In non-DS patients, IL-8 plasma levels were significantly reduced in the seventh day of ATRA treatment $(34.16 ; 6.99$ to $147.11 \mathrm{pg} \mathrm{mL}^{-1}$ in D0 vs. 10.9; 0 to $26.81 \mathrm{pg} \mathrm{mL}^{-1}$ in D7; $p=0.02$ ) whereas their levels did not discriminate between DS and non-DS development during the entire induction period (all $p>0.05$ in D0, D3, and D7). No significant differences were found in IL-6 levels between groups ( $p>0.05$ in D0-D7). Other cytokines tested were all undetectable in patients with APL or healthy controls.
\end{abstract}

Conclusions: We demonstrated that the modulation of IL-8 following ATRA treatment may occur regardless of the development of DS and, therefore, does not appear to be a predictive biomarker to monitor the APL-DS.

Keywords: Acute promyelocytic leukemia, Differentiation syndrome, Interleukin-6 (IL-6), Interleukin-8 (IL-8)

\footnotetext{
* Correspondence: eduardo.rego@fm.usp.br

${ }^{1}$ Hematology Division, Department of Medical Images, Hematology, and

Clinical Oncology, University of Sao Paulo at Ribeirao Preto Medical School,

Ribeirao Preto, Brazil

${ }^{2}$ Center for Cell Based Therapy, University of Sao Paulo at Ribeirao Preto

Medical School, Ribeirao Preto, Brazil

Full list of author information is available at the end of the article
}

(c) The Author(s). 2020 Open Access This article is licensed under a Creative Commons Attribution 4.0 International License, which permits use, sharing, adaptation, distribution and reproduction in any medium or format, as long as you give appropriate credit to the original author(s) and the source, provide a link to the Creative Commons licence, and indicate if changes were made. The images or other third party material in this article are included in the article's Creative Commons licence, unless indicated otherwise in a credit line to the material. If material is not included in the article's Creative Commons licence and your intended use is not permitted by statutory regulation or exceeds the permitted use, you will need to obtain permission directly from the copyright holder. To view a copy of this licence, visit http://creativecommons.org/licenses/by/4.0/ The Creative Commons Public Domain Dedication waiver (http://creativecommons.org/publicdomain/zero/1.0/) applies to the data made available in this article, unless otherwise stated in a credit line to the data. 


\section{Background}

Differentiation syndrome (DS) is a life-threatening adverse event that occurs in approximately $20-25 \%$ of patients with acute promyelocytic leukemia (APL) undergoing induction therapy with all-trans retinoic acid (ATRA) [1, 2]. During the APL-DS, changes in seric levels of cytokines [3], and in cellular adhesion/migration properties $[1,4,5]$, as well as endothelial damage [6] have been reported to be related to ATRA-driven DS. The in vitro release of pro-inflammatory cytokines such as interleukin (IL)-1 $\beta$, IL-6, IL-8, and tumor necrosis factor- $\alpha$ (TNF- $\alpha$ ) have been reported to coincide with ATRA-induced differentiation of APL blasts, which may lead in vivo to a systemic inflammatory response syndrome (SIRS) [3, 7]. Moreover, the ATRA-differentiating APL cells have increased ability to migrate from the blood flow into the tissues by upregulating molecules involved in cell adhesion (e.g.: ICAM: Intercellular Adhesion Molecule-1 and 2) and migration (e.g.: E-selectin and $\beta 2$-integrin) $[5,8]$.

The lung is the most clinically relevant target organ in APL-DS patients, which can develop distinct pulmonary complications [9]. Accordingly, it was experimentally demonstrated that increased expression of ICAM-1 on the lung of NOD/scid mice after ATRA therapy is important for the pulmonary infiltration of APL cells [10]. Moreover, the IL- 8 secretion by A549 alveolar epithelial cells support the chemotactic transmigration of ATRA-treated NB4 APL cells toward A549 cells [11]. In fact, IL-8 plays a important role in acute inflammation by activating and chemoattracting neutrophils [12]. Patients with acute myeloid leukemia (AML) that express lower levels of IL-8 have better survival outcomes [13]. Accordingly, the IL-8 receptor CXCR2 is an adverse prognostic factor in AML and its inhibition decreases the proliferation of AML cell lines and primary samples [14].

Despite the lack of biomarkers that predict development of DS, Shibakura et al. observed that serum levels of IL-8 were increased during the course of ATRA treatment in two patients who developed APL-DS [15]. To support these in vivo findings, the same authors confirmed that the in vitro IL-8 expression was also upregulated in leukemic primary cells from both patients with APL after incubation with ATRA [15]. Nevertheless, no previous study has investigated and compared the IL-8 plasma levels in the plasma of DS and non-DS patients with APL during the treatment with ATRA to determine whether this cytokine has the potential to predict the development of the APL-DS.

\section{Methods}

\section{Patients}

The patients were treated according to the International Consortium on APL protocol [16] and cytokine levels were also evaluated in the 17 patients with APL who developed (DS-group; $n=6$ ) or not (non-DS group; $n=11$ ) DS during the treatment with ATRA and anthracyclines. The diagnosis of DS was based on the presence of any signs and symptoms of dyspnea, renal failure, hypotension, fever, weight gain (greater than $5 \mathrm{Kg}$ ), edema and pulmonary congestion. Then, the clinical manifestations of DS were adequately managed following the European LeukemiaNet recommendations [17]. Samples from 11 healthy adult volunteers were used as controls.

\section{Cytokine quantification}

Plasma samples were obtained at diagnosis (D0), after three (D3) and seven (D7) days of treatment with ATRA and anthracyclines. Briefly, after centrifugation of heparinized peripheral blood, the plasma samples were immediately aliquoted and stored at $-80^{\circ} \mathrm{C}$ until the experiment was conducted. The concentrations of IL-8, IL-1 $\beta$, IL-6, IL-10, IL-12p70 and TNF in the plasma of patients with APL and healthy controls were measured once after collection of each individual samples by using the cytometric bead array assay (CBA-Human Inflammatory Cytokine Kit, BD Biosciences) according to the manufacturer's instructions. The standard curves concentrations for each cytokine ranged from 20 to 5000 $\mathrm{pg} / \mathrm{mL}$. Samples were acquired on the FACSCalibur flow cytometer (BD Biosciences) and analyzed using FCAP Array $^{\mathrm{TM}}$ software (BD Biosciences).

\section{Statistical analyses}

The plasma concentrations of each cytokine were compared among patients with APL at D0 and during the days of treatment with ATRA and anthracyclines (D3 and D7) using the Two-way ANOVA, followed by Tukey's post-test for the comparison between -DS and non-DS groups and Friedman's test, followed by Dunn's multiple comparison post-test when -DS and non-DS groups were gathered together. Fisher's two-tailed exact test (categorical variables) or Mann-Whitney $U$ test (continuous variables) was used to assess the possible differences between IL-6 and IL-8 levels and clinical parameters such as age, gender, WBC and Plt counts, fibrinogen concentration, relapse-risk and death during induction between DS and non-DS groups. Statistical analyses were performed using SPSS software (version 19.0; IBM Corp., Armonk, NY, USA). A $p$ value $<0.05$ was considered significant.

\section{Results}

Seventeen patients with APL (10 females, 7 males) with an age range of $19-72$ years (median age, $36 \pm 16$ years) diagnosed at the Clinics Hospital of Ribeirão Preto (HCFMRP), University of São Paulo, from March 2007 
through July 2013 were included in this study. All the six patients with DS presented with dyspnea, pulmonary infiltrates and unexplained fever and, in two cases there was evidence of kidney failure as well (severe DS). The symptoms started between 9th and 18th day of ATRA therapy. All but one recovered from the DS and achieved and remain in complete remission. Eight healthy controls (8 females, 3 males) were included as controls. Samples were collected only from control subjects with no history of fever within 1 week, use of any medications or drugs, pregnancy, and chronic diseases. In our cohort, IL-1 $\beta$, IL-10, IL-12p70 and TNF- $\alpha$ were not detected in the plasma of patients with APL regardless of the development of DS. These findings may due to the absence of such cytokines in the samples or to the fact that these cytokine concentrations are below the detection limit of the CBA (IL-1 $\beta$ : $<7.2 \mathrm{pg} / \mathrm{mL}$; IL-10: $<3.3 \mathrm{pg} / \mathrm{mL}$; IL12p70: $<1.9 \mathrm{pg} / \mathrm{mL}$; TNF- $\alpha$ : $<3.7 \mathrm{pg} / \mathrm{mL}$ ).

Table 1 shows the levels of IL- 6 and -8 at D0, after three and 7 days of treatment. IL- 6 and IL- 8 were not detected in healthy control group (data not shown). The distribution of the plasma concentration levels of IL-6 and IL-8 at D0 ranged from 0 to $83.74 \mathrm{pg} \mathrm{mL}^{-1}$ and from 0.83 to $238.60 \mathrm{pg} \mathrm{mL}^{-1}$, respectively. Although the median values of IL- 6 and IL- 8 were lower in the group of patients who developed DS compared to the non-DS group the differences were not significant (Fig. 1a-b; Table 1; Supplementary file 1; both $p>0.05$ ). At the D3, the median value of IL- 6 concentrations was higher in the DS group, but again the difference was not significant (Fig. 1a-b; Table 1; Supplementary file 1; $p=0.60$ ). In contrast, at the seventh day of treatment with ATRA, we observed that APL plasma samples in non-DS group exhibited significant decreased IL-8 levels (34.16; 6.99 to $147.11 \mathrm{pg} \mathrm{mL}^{-1}$ in D0 vs. 10.9 ; 0 to $26.81 \mathrm{pg} \mathrm{mL}^{-1}$ in D7; $p=0.02$ - Fig. 1b; Table 1; Supplementary file 1). Although there was a decrease in IL-8 levels in DS-group it was not significant $\left(23.09 ; 2.63\right.$ to $79.64 \mathrm{pg} \mathrm{mL}^{-1}$ in D0 vs. $6.2 ; 0$ to $17.24 \mathrm{pg} \mathrm{mL}^{-1}$ in $\mathrm{D} 7 ; p=0.06$ - Fig. $1 \mathrm{~b}$; Table 1; Supplementary file 1). In addition, there were no differences between the two groups in the IL-6 levels throughout treatment (Fig. 1a; Table 1; Supplementary file 1 ; all $p>0.05$ ). Of note, assessing our cohort, only $6 /$ 17 (2 from DS- and 4 from non-DS group) and 2/17 (1 from DS- and 1 from non-DS group; Supplementary file 1) patients with APL, respectively, for the levels of IL-6 and IL- 8 became undetectable at D7, such as observed in healthy controls. Moreover, our study not detected significant differences between IL-6 and IL-8 levels at D0/D3 (Fig. 1c; Supplementary file 1; both $p>0.05$ ) and D0/D7 (Fig. 1d; Supplementary file 1; both $p>0.05$ ) ratios when comparing DS- and non-DS groups.

Table 2 shows the distribution of the main clinical and laboratory variables in the groups of patients with low or high levels of IL-6 and IL-8 at diagnosis. Patients with WBC counts higher than $10^{9} / \mathrm{L}$ presented lower concentrations of IL-8 at diagnosis. In fact, with the exception of WBC counts ( $p=0.04$; Table 3; Supplementary file 1$)$, the clinical features and laboratory results of patients with APL at D0 were not associated with DS development (all $p>0.05$; Table 3; Supplementary file 1). Patients who develop (median value $6.2 \pm 5.9 \mathrm{pg} \mathrm{mL}^{-1}$ ) or not (median value $10.9 \pm 7.9 \mathrm{pg} \mathrm{mL}^{-1}$ ) the DS persisted with detectable low plasma concentrations of IL-8 after 7 days of treatment with ATRA. Finally, the variation of IL-8 levels in patients with APL following ATRA treatment occurred independently of the development or not of DS ( $p=0.002$; D0 vs. D7 of DS- and non-DS groups combined together - Fig. 1b; Supplementary file 1).

\section{Discussion}

The absence of IL-1 $\beta$, IL-10, IL-12p70 and TNF- $\alpha$ expression in our cohort of patients with APL, observed in the groups with and without DS, highlights the difference in cytokine profiles of APL and non-APL AML because Turzanski et al. and Sanchez-Correa et al. have

Table 1 Effects of ATRA and anthracyclines on the secretion of cytokines in APL patients with or without DS

\begin{tabular}{|c|c|c|c|c|}
\hline \multirow[t]{2}{*}{ Cytokine } & \multirow{2}{*}{$\begin{array}{l}\text { All patients, }(n= \\
\text { 17) }\end{array}$} & \multirow{2}{*}{$\begin{array}{l}\text { DS group, }(n=6) \\
\text { Median (range) }\end{array}$} & Non-DS group, $(n=11)$ & \multirow{2}{*}{$\begin{array}{l}P \text { - } \\
\text { value }^{1}\end{array}$} \\
\hline & & & Median (range) & \\
\hline \multicolumn{5}{|l|}{ IL-6 } \\
\hline D0 & $6.86(0.00,580.19)$ & $2.93(0.00,167.03)$ & $9.80(0.61,580.19)$ & 0.28 \\
\hline D3 & $4.92(0.00,83.74)$ & $17.39(0.00,83.74)$ & $4.92(0.00,26.04)$ & 0.60 \\
\hline D7 & $0.48(0.00,279.10)$ & $0.26(0.00,122.96)$ & $0.52(0.00,279.10)$ & 0.70 \\
\hline \multicolumn{5}{|l|}{ IL-8 } \\
\hline D0 & $25.92(2.63,147.11)$ & $23.10(2.63,79.64)$ & $34.16(6.99,147.11)$ & 0.33 \\
\hline D3 & $10.91(0.83,238.60)$ & $12.71(0.83,28.99)$ & $10.62(3.02,238.60)$ & 0.67 \\
\hline D7 & $9.37(0.00,26.81)$ & $6.20(0.00,17.24)$ & $10.91(0.00,26.81)$ & 0.31 \\
\hline
\end{tabular}

APL Acute promyelocytic leukemia, DS Differentiation syndrome

${ }^{1}$ Mann-Whitney $U$ test was used to compare cytokine plasma levels between DS and non-DS groups 


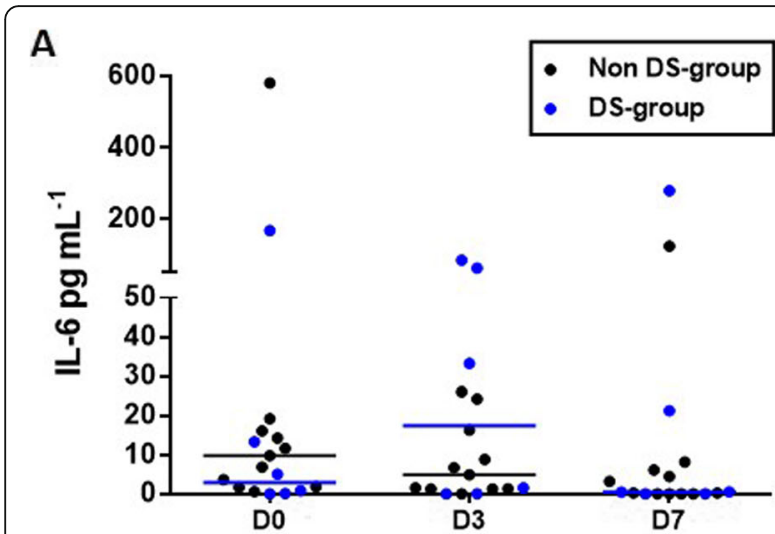

ATRA and anthracycline treatment

C

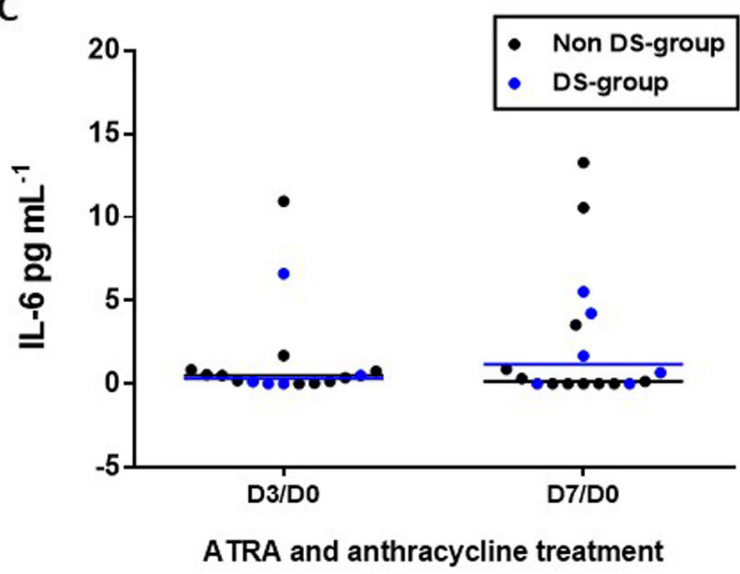

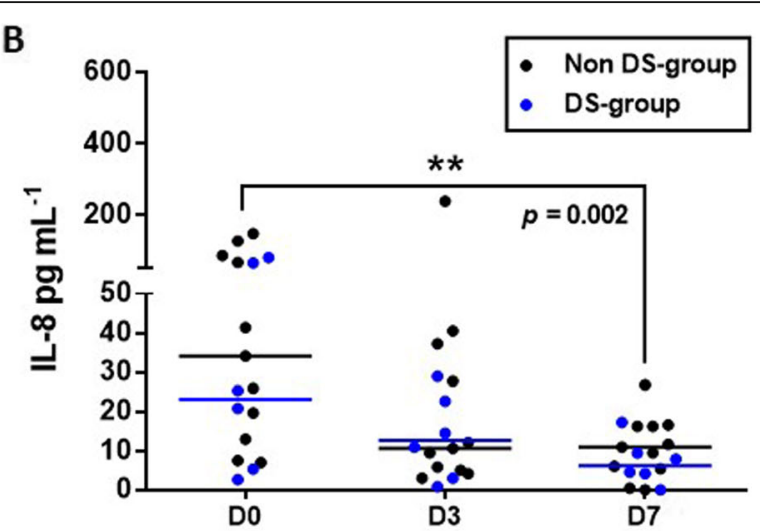

ATRA and anthracycline treatment

D

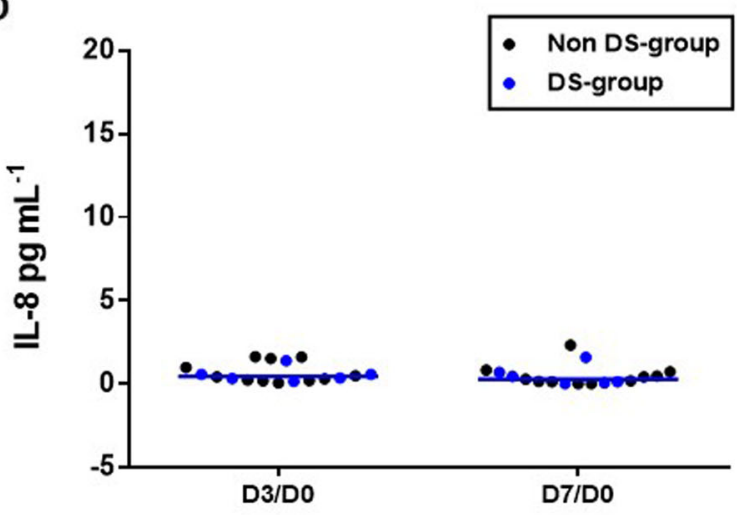

ATRA and anthracycline treatment

Fig. 1 IL-6 and IL-8 plasma levels in APL-DS patients during ATRA and anthracyclines treatment. a The comparison of the interleukin (IL) - 6 plasma levels between patients with APL treated with all-trans retinoic acid (ATRA) and anthracyclines who developed (DS-group; $n=6$ ) or not (non-DS group; $n=11$ ) the differentiation syndrome (DS) were unchanged. $\mathbf{b}$ ATRA and anthracyclines significantly reduced the IL-8 levels regardless of the DS development (D7 vs. D0 of DS and non-DS groups combined together, $p=0.002$ - Friedman's test, followed by Dunn's multiple comparison post-test). The IL-6 (c) and IL-8 (d) D3/D0 and D7/D0 ratios did not differ between DS- and non-DS patients with APL. The horizontal lines represent the median of cytokine plasma concentration in DS- (blue) and non-DS (black) groups

reported that IL-1 $\beta$ and IL-10 are detected in the plasma of patients with AML without $\mathrm{t}(15 ; 17)$ and may play a role in apoptosis-resistant phenotype and clinical outcome, respectively $[18,19]$.

In this study, among the cytokines examined, IL-6 and IL- 8 were the only ones detected on the plasma of patients with APL, but differentially modulated by treatment with ATRA over time. Similar to our results, Dubois et al. [1] demonstrated that the incubation of APL primary cells with ATRA did not modulate the IL-6 production but significantly decrease the levels of IL-8 in the supernatant. In addition, in contrast to the previous report, showing an relationship between high IL-8 serum levels and the occurrence of DS in two patients with APL [15], our data demonstrate that patients who develop or not the DS may persist with detectable low plasma concentrations of IL-8 after the first week of treatment, suggesting that the modulation of IL-8 levels in patients with APL following ATRA treatment may occur regardless of the DS development.

A key problem in the diagnostic process of DS is the lack of precise definitions of clinical criteria and biomarkers. In addition, the DS diagnosis is often challenging when the signs and symptoms attributable to DS occur in patients with APL who also develop complications such as pneumonia, cardiac toxicity, renal failure, and septic shock [6]. Considering the APL-DS patients with apparently no other complications, Montesinos et al. proposed criteria for APL-DS severity grading based on the presence of predefined signs and symptoms [20] but this classification has not been widely adopted in practice as occurred in the current study once the number of patients enrolled in the cohort did not allow a stratified analysis of the DS-group. Although the lower 


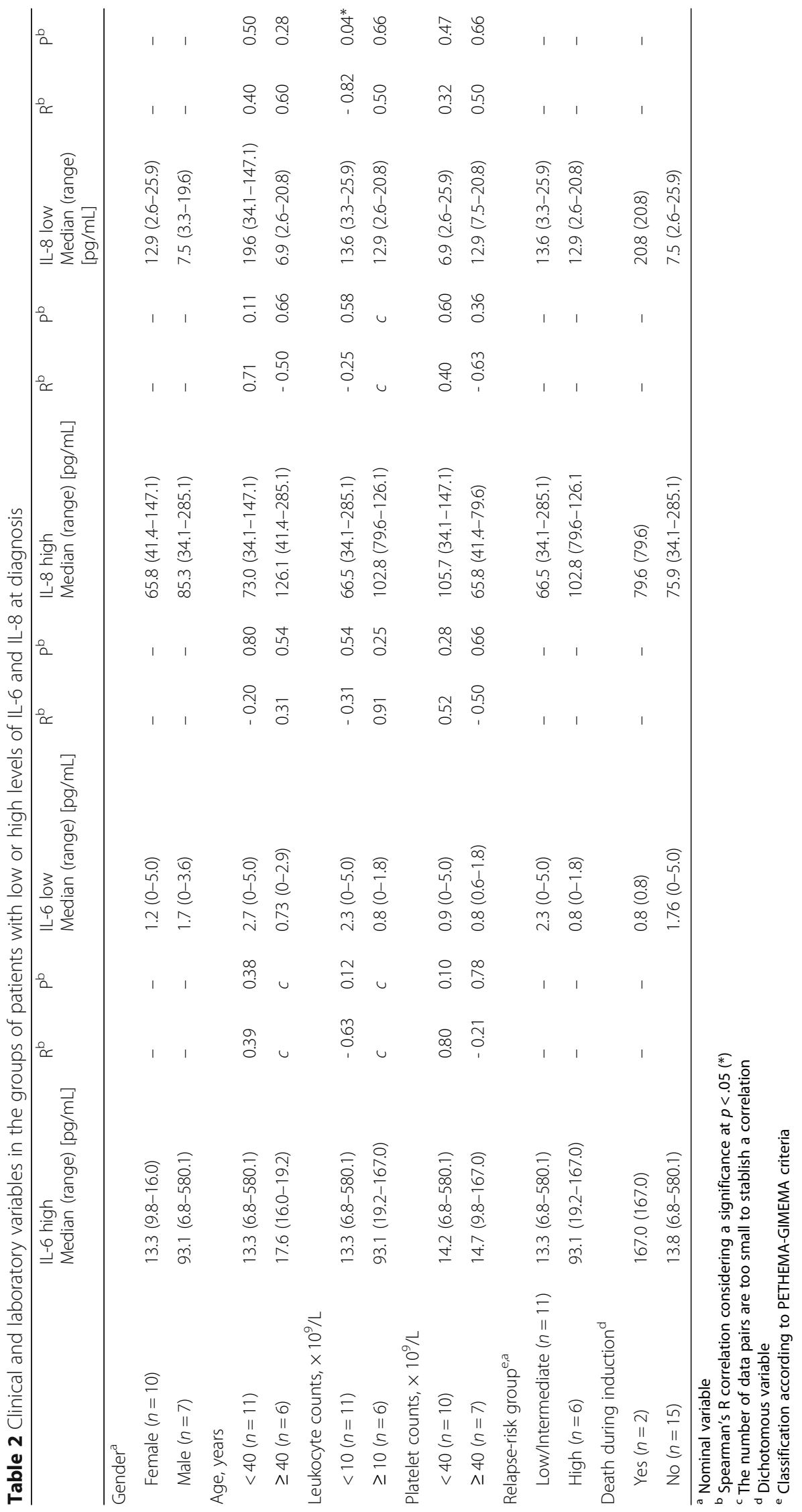


Table 3 Clinical characteristics and laboratory results at diagnosis of APL patients with or without DS

\begin{tabular}{|c|c|c|c|c|c|c|c|c|c|c|}
\hline \multirow[t]{2}{*}{ Variable at diagnosis } & \multicolumn{2}{|c|}{ All patients, $(n=17)$} & \multicolumn{4}{|l|}{ DS group, $(n=6)$} & \multicolumn{3}{|c|}{ Non-DS group, $(n=11)$} & \multirow{2}{*}{$\begin{array}{l}P \text { - } \\
\text { value }^{2}\end{array}$} \\
\hline & N. & $\%$ & Median (range) & $\mathrm{N}$ & $\%$ & Median (range) & N. & $\%$ & Median (range) & \\
\hline Gender & & & & & & & & & & 0.64 \\
\hline Female & 10 & 58.8 & & 3 & 50 & & 7 & 63.6 & & \\
\hline Male & 7 & 41.2 & & 3 & 50 & & 4 & 36.4 & & \\
\hline Age, years & & & $36.25(17.42,72.08)$ & & & $38.37(21,59.33)$ & & & $36.25(38.33,72.08)$ & 0.40 \\
\hline$<40$ & 7 & 41.2 & & 2 & 33.3 & & 5 & 45.5 & & \\
\hline$\geq 40$ & 10 & 58.8 & & 4 & 66.7 & & 6 & 54.5 & & \\
\hline Leukocyte counts, $\times 10^{9} / \mathrm{L}$ & & & $2.4(0.5,83.5)$ & & & $2.0(1.6,48.7)$ & & & $1.6(1.2,83.5)$ & $0.02^{*}$ \\
\hline$<10$ & 11 & 64.7 & & 2 & 33.3 & & 9 & 81.8 & & \\
\hline$\geq 10$ & 6 & 35.3 & & 4 & 66.7 & & 2 & 18.2 & & \\
\hline Platelet counts, $\times 10^{9} / \mathrm{L}$ & & & $36(5,110)$ & & & $43(39,71)$ & & & $28(14,110)$ & 0.98 \\
\hline$<40$ & 10 & 58.8 & & 3 & 50 & & 7 & 63.6 & & \\
\hline$\geq 40$ & 7 & 41.2 & & 3 & 50 & & 4 & 36.4 & & \\
\hline Relapse-risk group ${ }^{1}$ & & & & & & & & & & 0.10 \\
\hline Low/Intermediate & 11 & 64.7 & & 2 & 33.3 & & 9 & 81.8 & & \\
\hline High & 6 & 35.3 & & 4 & 66.7 & & 2 & 18.2 & & \\
\hline Fibrinogen (mg/dL) & & & $152.7(66,400)$ & & & $207.5(77,400)$ & & & $146.7(66,390)$ & 0.48 \\
\hline$<170$ & 8 & 50 & & 3 & 50 & & 5 & 50 & & \\
\hline$\geq 170$ & 8 & 50 & & 3 & 50 & & 5 & 50 & & \\
\hline Unknown & 1 & - & & - & - & & 1 & - & & \\
\hline Death during induction & & & & & & & & & & 0.10 \\
\hline Yes & 2 & 12.5 & & 2 & 33.3 & & 0 & 0 & & \\
\hline No & 15 & 87.5 & & 4 & 66.7 & & 11 & 100 & & \\
\hline
\end{tabular}

APL Acute promyelocytic leukemia, DS Differentiation syndrome

${ }^{1}$ Classification according to PETHEMA-GIMEMA criteria

${ }^{2}$ Fisher's two-tailed exact test was used to compare categorical variables. Mann-Whitney $\mathrm{U}$ test was used to compare continuous variables

* Indicate values statistically significant when $P<.05$

serum levels of IL-8 has been reported to be associated with longer survival in AML patients [13], the prognostic relevance of IL-8 in APL remains to be established in larger cohorts that accurately stratify the patients with APL for severity ranking of the DS.

\section{Study limitations}

Limitations of the current study include the small sample size from a single center as well as the retrospective study design. In addition, cytokine measurements were achieved by using a single method.

\section{Conclusions}

The present study demonstrated that ATRA treatment reduces the levels of IL-8 regardless of the occurrence of DS and, therefore, our findings do not support that IL-8 is a predictive biomarker for monitoring the development of the APL-DS.

\section{Supplementary information}

Supplementary information accompanies this paper at https://doi.org/10. 1186/s12885-020-07330-1.

Additional file 1. Clinical characteristics, laboratory results, and IL-6 and IL-8 levels in APL patients at DO and during the days of treatment with ATRA and anthracyclines (D3 and D7).

\section{Abbreviations}

AML: Acute myeloid leukemia; APL: Acute promyelocytic leukemia; ATRA: Alltrans retinoic acid; DS: Differentiation syndrome; ICAM: Intercellular Adhesion Molecule; IL: Interleukin; SIRS: Systemic inflammatory response syndrome;

TNF-a: Tumor necrosis factor-a

\section{Acknowledgements}

We thank Prof. Lorena Lôbo de Figueiredo Pontes and Maria Isabel Ayrosa Madeira from the Hematology Division, Department of Medical Images, Hematology, and Clinical Oncology, University of Sao Paulo at Ribeirao Preto Medical School, for the acquisition of clinical data.

\section{Authors' contributions}

EMR conceived and designed the study, wrote and revised the manuscript. LYA carried out the experiments, performed a bibliographic study and wrote the manuscript. PSS performed the flow cytometry sample acquisition. LYA, PSS and DAPM analyzed data. DAPM, ASGL and MSB collected patient 
samples. LCAK, LYA, DAPM, SCB and APL provided clinical data. All authors discussed the results and contributed to the final manuscript. The author(s) read and approved the final manuscript.

\section{Funding}

This work was supported by a grant from Fundação de Apoio à Pesquisa do Estado de Sao Paulo (FAPESP; grant no. 2013/08135-2). This grant supported all materials and reagents necessary for the development of the present work. LYA and DAPM received FAPESP fellowships (grants no. 2016/02713-2 and 2017/23117-1, respectively). The funding bodies played no role in the design of the study and collection, analysis, and interpretation of data and in writing the manuscript.

\section{Availability of data and materials}

All data generated or analysed during this study are included in this article and in the Supplementary file 1.

\section{Ethics approval and consent to participate}

This study was approved by the local Research Ethics Comitee of the Medical School of Ribeirao Preto, University of Sao Paulo, Ribeirão Preto, São Paulo, Brazil (CAAE: 05060818.9.0000.5440) and all samples were obtained with written informed consent.

\section{Consent for publication}

Not applicable.

\section{Competing interests}

All authors declare no potential financial conflicts.

\section{Author details}

${ }^{1}$ Hematology Division, Department of Medical Images, Hematology, and Clinical Oncology, University of Sao Paulo at Ribeirao Preto Medical School, Ribeirao Preto, Brazil. ${ }^{2}$ Center for Cell Based Therapy, University of Sao Paulo at Ribeirao Preto Medical School, Ribeirao Preto, Brazil. ${ }^{3}$ Hemostasis Laboratory, Hospital das Clínicas da Faculdade de Medicina de Ribeirão Preto, University of Sao Paulo, Ribeirao Preto, Brazil. ${ }^{4}$ Hematology Division, LIM31, Faculdade de Medicina, University of Sao Paulo, Av Dr Eneas Carvalho de Aguiar 155, 1st Floor, Hemocentro, São Paulo, SP CEP05403-000, Brazil.

Received: 11 June 2020 Accepted: 24 August 2020

Published online: 28 August 2020

\section{References}

1. Rego EM, De Santis GC. Differentiation syndrome in promyelocytic leukemia: clinical presentation, pathogenesis and treatment. Mediterr J Hematol Infect Dis. 2011;3:e2011048.

2. Stahl M, Tallman MS. Differentiation syndrome in acute promyelocytic leukaemia. Br J Haematol. 2019:187:157-62.

3. Dubois C, Schlageter MH, Gentile AD, Balitrand N, Toubert ME, Krawice I, et al. Modulation of IL-8, IL-1 beta, and G-CSF secretion by all-trans retinoic acid in acute promyelocytic leukemia. Leukemia. 1994;8:1750-7.

4. Marchetti M, Falanga A, Giovanelli S, Oldani E, Barbui T. All-trans retinoic acid increases adhesion to endothelium of the human promyelocytic leukaemia cell line NB4. Br J Haematol. 1996;93:360-6.

5. Larson RS, Brown DC, Sklar LA. Retinoic acid induces aggregation of the acute promyelocytic leukemia cell line NB-4 by utilization of LFA-1 and ICAM-2. Blood. 1997:90:2747-56.

6. Seale J, Delva L, Renesto P, Balitrand N, Dombret H, Scrobohaci ML, et al. All-trans retinoic acid rapidly decreases cathepsin $\mathrm{G}$ synthesis and mRNA expression in acute promyelocytic leukemia. Leukemia. 1996;10:95-101.

7. Tang L, Chai W, Ye F, Yu Y, Cao L, Yang M, et al. HMGB1 promotes differentiation syndrome by inducing hyperinflammation via MEK/ERK signaling in acute promyelocytic leukemia cells. Oncotarget. 2017:8:27314-27.

8. Brown DC, Tsuji H, Larson RS. All-trans retinoic acid regulates adhesion mechanism and transmigration of the acute promyelocytic leukaemia cell line NB-4 under physiologic flow. Br J Haematol. 1999;107:86-98.

9. Luesink $\mathrm{M}$, Jansen $\mathrm{JH}$. Advances in understanding the pulmonary infiltration in acute promyelocytic leukaemia. Br J Haematol. 2010;151:209-20.

10. Ninomiya M, Kiyoi H, Ito M, Hirose Y, Ito M, Naoe T. Retinoic acid syndrome in $\mathrm{NOD} /$ scid mice induced by injecting an acute promyelocytic leukemia cell line. Leukemia. 2004;18:442-8.
11. Tsai WH, Hsu HC, Lin CC, Ho CK, Kou YR. Role of interleukin-8 and growthregulated oncogene-alpha in the chemotactic migration of all-trans retinoic acid-treated promyelocytic leukemic cells toward alveolar epithelial cells. Crit Care Med. 2007;35:879-85.

12. Harada A, Sekido N, Akahoshi T, Wada T, Mukaida N, Matsushima K. Essential involvement of interleukin-8 (IL-8) in acute inflammation. J Leukoc Biol. 1994;56:559-64

13. Kornblau SM, McCue D, Singh N, Chen W, Estrov Z, Coombes KR. Recurrent expression signatures of cytokines and chemokines are present and are independently prognostic in acute myelogenous leukemia and myelodysplasia. Blood. 2010;116:4251-61.

14. Schinke C, Giricz O, Li W, Shastri A, Gordon S, Barreyro L, et al. IL8-CXCR2 pathway inhibition as a therapeutic strategy against MDS and AML stem cells. Blood. 2015;125:3144-52.

15. Shibakura M, Niiya K, Niiya M, Asaumi N, Yoshida C, Nakata Y, et al. Induction of CXC and CC chemokines by all-trans retinoic acid in acute promyelocytic leukemia cells. Leuk Res. 2005;29:755-9.

16. Rego EM, Kim HT, Ruiz-Argüelles GJ, Undurraga MS, Uriarte Mdel R, Jacomo $\mathrm{RH}$, et al. Improving acute promyelocytic leukemia (APL) outcome in developing countries through networking, results of the International Consortium on APL. Blood. 2013;121:1935-43.

17. Sanz MA, Grimwade D, Tallman MS, Lowenberg B, Fenaux P, Estey EH, et al. Management of acute promyelocytic leukemia: recommendations from an expert panel on behalf of the European LeukemiaNet. Blood. 2009;113: 1875-91.

18. Turzanski J, Grundy M, Russell NH, Pallis M. Interleukin-1 beta maintains an apoptosis-resistant phenotype in the blast cells of acute myeloid leukaemia via multiple pathways. Leukemia. 2004;18:1662-70.

19. Sanchez-Correa B, Bergua JM, Campos C, Gayoso I, Arcos MJ, Bañas H, et al. Cytokine profiles in acute myeloid leukemia patients at diagnosis: survival is inversely correlated with IL-6 and directly correlated with IL-10 levels. Cytokine. 2013;61:885-91.

20. Montesinos P, Bergua JM, Vellenga E, Rayón C, Parody R, de la Serna J, et al. Differentiation syndrome in patients with acute promyelocytic leukemia treated with all-trans retinoic acid and anthracycline chemotherapy: characteristics, outcome, and prognostic factors. Blood. 2009;113:775-83.

\section{Publisher's Note}

Springer Nature remains neutral with regard to jurisdictional claims in published maps and institutional affiliations.

\section{Ready to submit your research? Choose BMC and benefit from:}

- fast, convenient online submission

- thorough peer review by experienced researchers in your field

- rapid publication on acceptance

- support for research data, including large and complex data types

- gold Open Access which fosters wider collaboration and increased citations

- maximum visibility for your research: over $100 \mathrm{M}$ website views per year

At BMC, research is always in progress.

Learn more biomedcentral.com/submissions 